DOI: https://doi.org/10.24127/ajpm.v9i3.2951

\title{
PENGEMBANGAN SPACE GEOMETRY FLIPBOOK AUDIO VISUAL BERBASIS DIGITAL LITERACY UNTUK SISWA SMP
}

\author{
Siti Nur Hasanah ${ }^{1}$, Moh. Mahfud Effendi ${ }^{2}$, Octavina Rizky Utami Putri ${ }^{3 *}$ \\ 1,2,3* Pendidikan Matematika, Universitas Muhammadiyah Malang, Malang, Indonesia \\ *Corresponding author. Jl. Raya Tlogomas No. 246, 65144, Malang, Indonesia

E-mail: $\frac{\frac{\text { snhazanah16@gmail.com }}{\text { mahfud@umm.ac.id }}{ }^{2)}}{\frac{{ }_{\text {octavina@umm.ac.id }}^{3 *)}}{3^{*}}}$

Received 18 July 2020; Received in revised form 09 September 2020; Accepted 23 September 2020

\begin{abstract}
Abstrak
Penelitian ini bertujuan untuk menghasilkan media space geometry flipbook (SGF) audio visual berbasis digital literacy untuk siswa SMP yang valid, praktis dan efektif. Jenis penelitian ini merupakan research and development dengan tahap analysis, design, development, implementation, dan evaluation yang berorientasi pada produk. Subjek dalam penelitian ini adalah siswa SMP yang berkemampuan tinggi, sedang, dan rendah. Instrumen yang digunakan meliputi lembar validasi, lembar angket, lembar observasi, dan tes evaluasi. Hasil penelitian menunjukan bahwa media SGF yang dikembangkan valid menjadi sarana belajar siswa. Media ini praktis digunakan karena siswa mampu mengoperasikan media dengan lancar, serta $74 \%$ siswa dapat menyelesaikan soal evaluasi dengan ketercapaian skor minimal 70. Hasil observasi pada siswa memperoleh persentase 78,25\% terkait ketercapaian digital literacy.
\end{abstract}

Kata kunci: Audio visual; Digital Literacy; Pengembangan; Space Geometry Flipbook.

\begin{abstract}
This study aims to produce a valid, practical, and effective media space geometry flipbook (SGF) based on digital literacy for junior high school students. This type of research is research and development with the stages of analysis, design, development, implementation, and evaluation that are product-oriented. The subjects in this study were high, medium, and low-ability junior high school students. The instruments used include validation sheets, questionnaire sheets, observation sheets, and evaluation tests. The results showed that the developed SGF media was valid as a means of learning for students. This media is practical to use because students can operate the media smoothly, and $74 \%$ of students can complete evaluation questions with a minimum score of 70 . The observation results in students obtained a percentage of $78.25 \%$ related to the achievement of digital literacy.
\end{abstract}

Keywords: Audio visual; development; digital literacy; space geometry flipbook.

This is an open access article under the Creative Commons Attribution 4.0 International License

\section{PENDAHULUAN}

Pada zaman modern ini, perubahan telah terjadi begitu cepat dan signifikan, namun pendidikan tetap merupakan hal penting bagi kehidupan masyarakat. Kualitas pendidikan juga harus dikembangkan dengan melakukan perubahan dalam memperbaiki proses pembelajaran (Iswara, Ariyanto, \& Sutarni, 2012). Fakta di lapangan, banyak siswa lebih suka bermain gadget dari pada membaca buku. Oleh karena itu, guru dituntut untuk menciptakan pembelajaran yang menarik untuk meningkatkan motivasi dan hasil belajar siswa (Nurseto, 2012). Kecenderungan siswa untuk lebih memprioritaskan penggunaan gadget dapat dimanfaatkan ke arah pembelajaran yang lebih efektif, 
DOI: https://doi.org/10.24127/ajpm.v9i3.2951

yaitu dengan media pembelajaran (Aditya, 2018).

$$
\text { Media pembelajaran }
$$

matematika sebagai alat untuk meningkatkan motivasi belajar siswa. Dengan begitu, pendidik akan lebih mudah dalam menyampaikan pembelajaran (N. Hayati, Ahmad, \& Harianto, 2017; Setyono, Eka, Deswita, \& Belakang, 2017). Saat ini media pembelajaran sudah dikembangkan melalui teknologi dalam bentuk animasi yang dapat ditambahkan audio, sehingga memudahkan siswa dalam menggali informasi, selain itu juga menciptakan suasana belajar yang kondusif, efektif dan efisien (Assar, 2015; Lestari, Sunardi, \& Suryani, 2017).

Anggapan bahwa matematika adalah pelajaran yang sulit dan hanya berkaitan dengan rumus, berimplikasi pada tingkat pemahaman siswa yang sangat rendah. Salah satunya berkaitan dengan materi bangun ruang, mulai dari penyebutan nama, bentuk, sampai menemukan luas permukaan dan volume, serta mengaplikasikan rumus tersebut dalam menyelesaikan suatu masalah (Ainiyah \& Sugiyono, 2016). Terlebih pada bangun ruang sisi lengkung yang memiliki tingkat keabstrakan tinggi dalam pembelajaran matematika di kelas IX (Astuti, 2019).

Penelitian tentang integrasi teknologi dalam pendidikan menunjukkan bahwa sistem pembelajaran ICT (Information and Communication Technologies) di kelas bermanfaat bagi siswa yang belajar matematika (Andini, Fitriana, \& Budiyono, 2018). Pembelajaran berbasis ICT merupakan sebuah proses yang memanfaatkan kecanggihan teknologi yang berhubungan dengan komputer dan telekomunikasi (Chaidar, 2014; Suryani, 2016). Oleh karenanya, diperlukan kemampuan siswa dalam teknologi.

Kemampuan individu dalam mengoperasikan teknologi digital mulai dari menggali informasi sampai berkomunikasi dalam membangun relasi disebut digital literacy (Kurniawati \& Baroroh, 2016). Berdasarkan kurikulum 2013, pembelajaran menggunakan media digital cukup efektif, maka dari itu digital literacy harus dikembangkan agar siswa tidak hanya mampu menggunakan alat elektronik dan komunikasi (Tim GLN Kemendikbud, 2017). Melainkan juga mampu mengembangkan digital literacy yang mencakup 4 aspek yaitu pembelajaran sikap, kemampuan dalam bersosialisasi, teknis, serta kognitif sebagai respon terhadap era digital (Rahayu \& Mayasari, 2018).

Salah satu media digital yang cukup efektif digunakan dalam pembelajaran matematika adalah flipbook. Flipbook maker pro adalah suatu software yang mengubah tampilan PDF layaknya sebuah buku yang memberikan pembaharuan dalam proses pembelajaran di kelas (Haryanti \& Saputro, 2016). Flipbook merupakan media digital yang tidak hanya menyajikan teks, melainkan juga animasi, suara, dan video (Lestari et al., 2017). Media flipbook telah dikembangkan sebelumnya, diantaranya Setyono et al., (2017) mengembangkan media flipbook menggunakan Macromedia Flash berupa CDpembelajaran pada materi bangun ruang kelas VIII. Haryanti \& Saputro (2016) mengembangkan media flipbook berbasis discovery learning pada konsep segitiga.

Berdasarkan media yang telah dikembangkan sebelumnya, diperlukan inovasi lebih lanjut terkait dengan 
penggunaan audio visual. Menurut Syarifuddin \& Muadip (2016), media audio visual dapat mendorong minat belajar, memperjelas dan mempermudah konsep yang kompleks dan abstrak menjadi sederhana. Oleh sebab itu, tujuan penelitian ini adalah menghasilkan media space geometri flipbook audio visual berbasis digital literacy yang valid, praktis, dan efektif.

\section{METODE PENELITIAN}

Jenis penelitian ini merupakan Research and Development. Desain pengembangan media yang digunakan adalah desain pengembangan instruksional ADDIE (Analysis, Design, Development, Implementation, Evaluation) yang berorientasi pada produk. Pada pelaksanaan dan penerapannya, Model ADDIE adalah: (1) Analysis, dalam tahap ini dilakukan analisis karakteristik siswa, dan kurikulum sebagai acuan bahwa media space geometry flipbook (SGF) efisien, (2) Design, dalam tahap ini peneliti membuat kerangka, merancang serta membuat media SGF, (3) Development, dalam tahap ini pembuatan media SGF dengan menggunakan software flipbook maker, kemudian media SGF dan instrumen divalidasi oleh dosen ahli (4) Implementation, pada tahap ini penerapan media SGF dan instrumen, jika dinyatakan valid oleh validator maka media dapat diuji cobakan kepada siswa. Subjek dalam penelitian ini adalah 9 siswa kelas IX SMP yang berkemampuan tinggi, sedang, dan rendah. Dalam tahap ini pemberian soal evaluasi pada siswa dilakukan untuk mengetahui keefektifan media SGF. Penyebaran angket dilakukan juga untuk mendapatkan data terkait kepraktisan media SGF, (5) Evaluation dalam tahap ini penilaian media yang telah dihasilkan dan diujicobakan.

Media SGF yang dikembangkan ini diuji kevalidan, kepraktisan dan keefektifannya. Instrumen penelitian yang digunakan berupa lembar validasi, angket respon, observasi, dan tes evaluasi. Data hasil validasi dianalisis sesuai dengan aspek yang diamati yang meliputi materi, ilustrasi, kualitas dan tampilan media serta manfaatnya oleh validator, dan hasilnya dikategorikan seperti pada pada Tabel 1 .

Tabel 1. Kriteria kevalidan

\begin{tabular}{ccc}
\hline Nilai Kevalidan & Tingkat Kevalidan \\
\hline $0 \leq \bar{V}<25$ & Tidak valid & \\
\hline $25 \leq \bar{V}<50$ & Kurang valid & \\
\hline $50 \leq \bar{V}<75$ & Valid & \\
\hline $75 \leq \bar{V} \leq 100$ & Sangat valid & \\
\hline Adaptasi dari & (Putri & \& \\
Zukhrufurrohmah, 2019) &
\end{tabular}

Saran dari validator disajikan agar dapat merevisi media SGF yang lebih baik. Media dan instrumen dikatakan valid jika masuk interpretasi minimal valid. Angket respon siswa memuat 5 indikator yaitu kreatif, efektif, efisien, dan menarik. Respon siswa dianggap positif minimal $70 \%$ siswa mengisi angket dengan setuju (Willy Arif Indhaka, Eko Supraptono, 2016). Lembar observasi digunakan untuk mengetahui digital literacy siswa, memuat empat aspek yaitu sikap, sosial, teknis, dan kognitif. Lembar tes digunakan untuk mengukur penguasaan materi, yang memuat 3 soal uraian terkait luas dan volume bangun ruang sisi lengkung. Media dinyatakan efektif jika minimal $70 \%$ siswa memperolah nilai lebih dari 70 dan hasil pengamatan masuk kategori baik. 
DOI: https://doi.org/10.24127/ajpm.v9i3.2951

\section{HASIL DAN PEMBAHASAN}

Media yang berkualitas serta dapat mendukung proses pembelajaran siswa menjadi menarik dan mulai digunakan oleh guru. Penggunaan media ini dapat menambahkan kemajuan siswa dalam belajar serta membantu proses interaksi siswa dengan guru (Fitria, Mustami, \& Taufiq, 2017). Produk yang dihasilkan dalam penelitian ini adalah space geometry flipbook audio visual berbasis digital literacy dengan berbantuan aplikasi kvsoft flipbook maker. Media yang dikembangkan memuat materi bangun ruang sisi lengkung yaitu memuat tabung, kerucut, dan bola. Terdapat beberapa bagian dalam media yang meliputi petunjuk penggunaan, uraian materi, video ilustrasi, video penjelasan rumus luas permukaan dan volume serta contoh soal.

Pada halaman pertama saat membuka media SGF musik menyala secara otomatis dan terdapat daftar isi yang berisi animasi, petunjuk penggunaan, dan profil penulis. Selanjutnya, pada halaman kedua terdapat mind mapping dengan tombol yang tidak terlihat pada setiap gambar bangun ruang. Ketika kursor diarahkan kepada gambar maka kursor berubah tampilan menjadi tangan, artinya gambar tersebut dapat di klik untuk menampilkan sub bab materi yang dibahas pada halaman selanjutnya. Tampilan halaman pertama media SGF disajikan seperti pada Gambar 1.

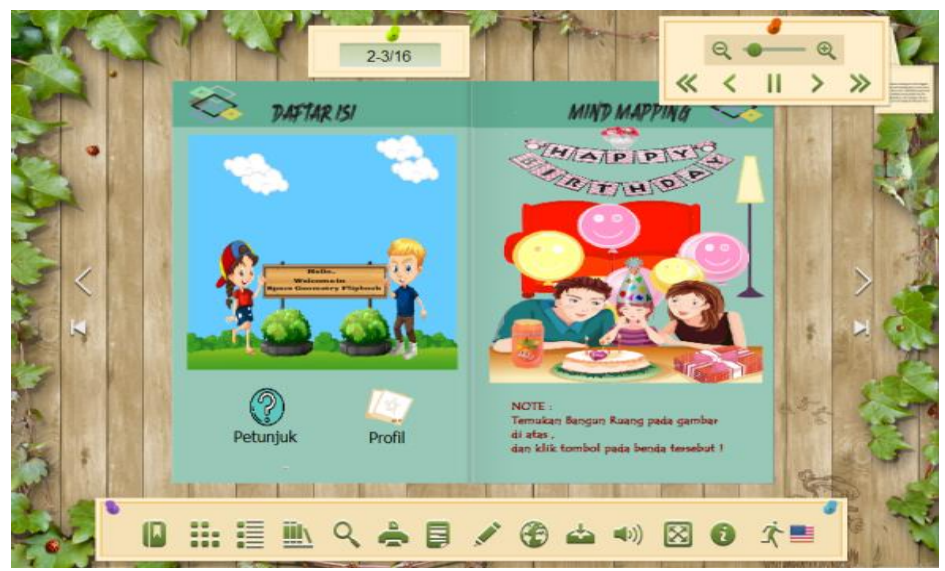

Gambar 1. Tampilan halaman pertama media Space Geometry Flipbook

Tabel 2. Perbedaan produk acuan dengan produk yang dikembangkan

\begin{tabular}{cll}
\hline No & \multicolumn{1}{c}{ Produk Acuan } & \multicolumn{1}{c}{ Produk yang telah dikembangkan } \\
\hline 1 & Tidak menggunakan animasi & Terdapat animasi \\
2 & Menggunakan peta konsep & Menggunakan mind mapping \\
3 & Tidak menggunakan musik & Menggunakan musik \\
4 & Terdapat video & $\begin{array}{l}\text { Terdapat video ilustrasi dan video penjelasan } \\
\text { rumus }\end{array}$ \\
\hline
\end{tabular}

Proses penelitian dan pengembangan yang telah dilakukan yaitu berdasarkan hasil observasi awal di sekolah dan mengacu pada produk yang sebelumnya pernah dikembangakna. Akan tetapi terdapat 
beberapa perbedaan antara produk yang akan dikembangkan dengan produk yang sudah pernah dihasilkan. Adapun perbedaan produk acuan dengan produk yang dikembangkan dapat dilihat pada tabel 2.

A. Validasi Media dan Materi

Proses validasi dilakukan untuk mengetahui tingkat keabsahan dari media SGF yang dikembangkan. Terdapat dua validator yang berkontribusi dalam proses validasi terkait penelitian yang dikaji yaitu dosen Pendidikan Matematika dan satu guru mata pelajaran matematika. Gambaran penilaian tersebut secara terperinci ditunjukan pada diagram Gambar 2.

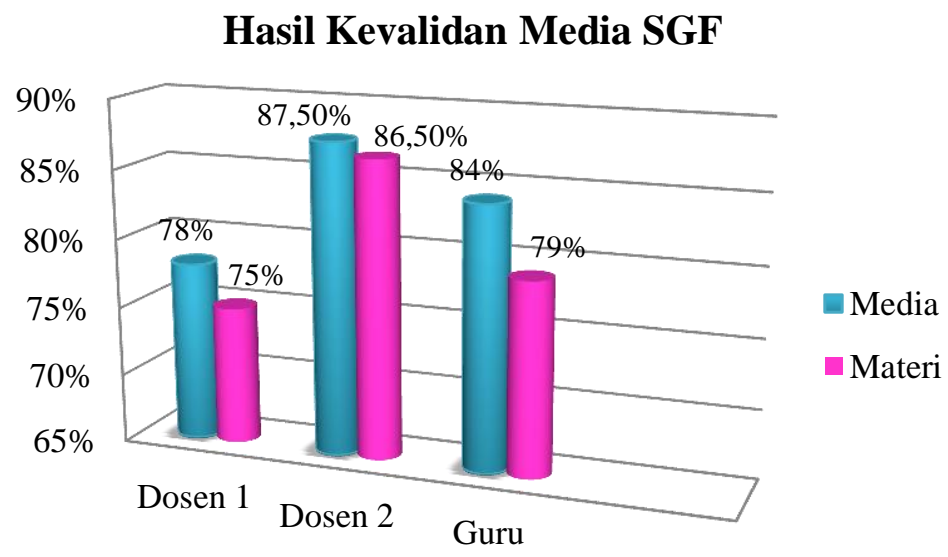

Gambar 2. Hasil validasi media SGF

Berdasarkan Gambar 2 dapat disimpulkan bahwa hasil validasi oleh dosen 1 memberikan penilaian terhadap materi yang telah sesuai dengan $\mathrm{KD}$, demikian pula dengan indikator yang dikembangkan serta penyajian materi sudah sesuai dan berurutan, dengan persentase $75 \%$, selain itu, penilaian terhadap media telah sesuai pada ilustrasi, tampilan media serta manfaatnya dengan hasil persentase $78 \%$ masuk pada kategori valid dengan sedikit revisi. Hasil validasi oleh dosen 2 memberikan penilaian sangat sesuai dengan $\mathrm{KD}$ dan indikatornya, serta penyajian materi juga sudah sesuai dan berurutan dengan persentase $86.50 \%$, kemudian untuk penilaian media sangat sesuai pada ilustrasi, tampilan media serta manfaat media dengan persentase $87.50 \%$ masuk pada kategori valid tanpa revisi.
Sedangkan hasil validasi guru memperoleh persentase materi $79 \%$ dengan penilaian yang sesuai pada KD dan indikator yang dikembangkan serta penyajian materi sudah sesuai dari yang mudah ke sukar sehingga memudahkan siswa dalam menguasai materi, kemudian untuk penilaian media telah sesuai pada ilustrasi, tampilan media serta manfaatnya mendapatkan hasil persentase $84 \%$ dan masuk pada kategori valid dengan sedikit revisi. Penelitian ini serupa dengan penelitian S. Hayati, Budi, \& Handoko (2015) bahwa validasi tiap aspek sudah memiliki kategori valid terhadap media dan materi dengan rata-rata persentase secara keseluruhan 95,87\%.

Salah satu saran yang diterima dari dosen, yakni tentang perbaikan media untuk mengurangi teks yang terlalu banyak sehingga tulisan terlalu 
rapat dan terlihat kurang bagus serta saran dari guru, yakni penyajian lebih disederhanakan tetapi mudah dimengerti oleh siswa.

\section{B. Kepraktisan}

Kepraktisan suatu media dapat ditinjau dari terlaksananya penelitian ini dan kendala yang dialami selama kegiatan uji coba berlangsung. Dalam pelaksanaan pengoperasian media SGF yang dikembangkan hanya membutuhkan waktu 90 menit kemudian 45 menit untuk menyelesaikan soal evaluasi yang yang telah disusun. Siswa dapat mengoperasikannya dengan lancar karena terdapat petunjuk penggunaan dan fungsi tombol-tombol yang terdapat pada bagian awal Media SGF. Kendala yang didapat, siswa tidak mengerti pada bagian mind mapping. Selain itu, tidak bekerjanya media SGF yang dikembangkan pada sebagian laptop yang belum terinstall program video player. Kendala ini dapat diatasi dengan cara menginstall program video player pada laptop milik siswa.

Uji coba terbatas dilakukan dengan subjek sebanyak 9 siswa SMP kelas IX. Subjek yang dipilih adalah siswa yang memberikan respon positif terhadap pembelajaran dan Media SGF. Representasi hasil angket respon siswa disajikan pada Gambar 3.

\section{Respon Positif Siswa}

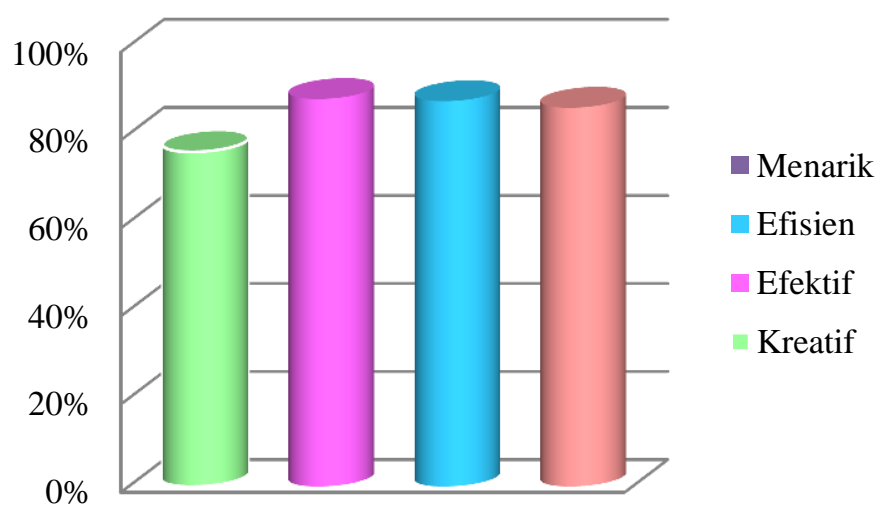

Gambar 3. Grafik Respon Positif Siswa terhadap media SGF

Berdasarkan Gambar 3, pada aspek kreatif terdiri dari 4 pertanyaan, menunjukkan data bahwa media SGF merangsang pikiran siswa dengan persentase $76 \%$ masuk kategori positif. Aspek efektif memuat enam pernyataan. Siswa menyatakan media SGF menyajikan komponen materi secara jelas dan mengaitkan materi dengan perkembangan teknologi yang terjadi dengan persentase $88 \%$ masuk kategori positif. Aspek efisien memuat dua pernyataan, $87.50 \%$ siswa menyatakan bahwa media SGF meningkatkan kualitas belajar siswa serta siswa mampu menguasai materi masuk kategori positif. Selanjutnya aspek menarik mencakup 5 pertanyaan, $86 \%$ siswa menyatakan tampilan media SGF jelas dan mudah dipahami serta menampilkan ilustrasi yang mendukung materi pelajaran yang berkaitan dengan lingkungan masuk kategori positif.

Hasil uji coba yang dilakukan terkait dengan proses penerapan media yang dikembangkan ini, serta cara mengatasi kendala yang terjadi selama proses penggunaan, dapat disimpulkan 
bahwa media SGF yang dikembangkan sudah memenuhi kriteria praktis untuk digunakan sebagai salah satu sarana belajar siswa. Temuan ini relevan dengan penelitian S. Hayati et al. (2015) bahwa Flipbook dapat meningkatkan kemampuan siswa.

\section{Keefektifan}

Setelah penilaian selesai dilakukan, siswa dipersilahkan untuk menyelesaikan soal evaluasi. $74 \%$ siswa dapat menyelesaikan soal evaluasi dengan batas minimum 70 poin.

Di samping analisis hasil jawaban soal evaluasi, kegiatan pengamatan pada siswa yang menjadi sasaran uji coba penggunaan media juga dilakukan. Pengamatan ini dilakukan untuk mengetahui seberapa baik digital literacy (Rahayu \& Mayasari, 2018) dan diperoleh penilaian secara terperinci yang ditunjukkan pada Gambar 4 .

\section{Persentase Tingkat Literasi Digital}

$\square$ Sikap $\square$ Sosial-emosional $\quad$ Teknis $\quad$ Kognitif

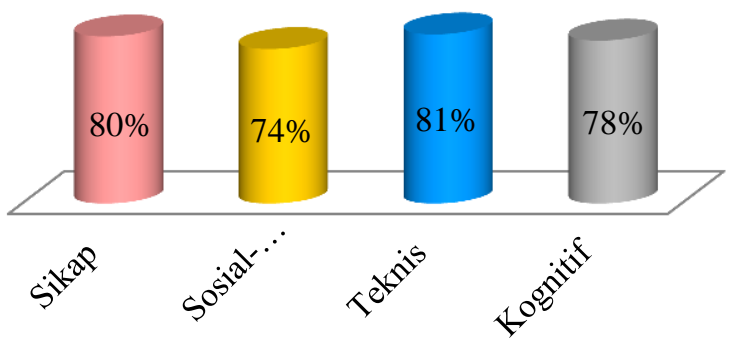

Gambar 4. Persentase Tingkat Aspek Digital Literacy

sikap memuat 6 pernyataan, menunjukkan bahwa media SGF dapat mendukung belajar siswa dengan presentase $80 \%$ masuk kategori sangat baik. Aspek sosial emosional mencakup 3 pernyataan yang menunjukkan data bahwa siswa bersosialisasi secara online dan berkolaborasi dalam melakukan tugas dengan presentase $74 \%$ masuk kategori baik. Aspek teknis memuat 3 pernyataan bahwa $81 \%$ siswa memiliki keterampilan operasional dalam menggunakan media digital untuk belajar masuk kategori sangat baik. Selanjutnya aspek kognitif yang memuat 3 pernyataan bahwa $78 \%$ siswa mampu menemukan informasi dengan jelas serta dapat memahami materi dengan baik masuk kategori sangat baik. Oleh sebab itu, media ini dapat disimpulkan efektif.

\section{KESIMPULAN DAN SARAN}

Media SGF yang telah dikembangkan telah memenuhi kriteria valid, praktis, dan efektif. Temuan ini menunjukkan bahwa hasil belajar siswa saat menggunakan media SGF meningkat daripada persentase sebelumnya. Karena media SGF mendorong motivasi siswa serta mempermudah siswa dalam menguasai materi bangun ruang sisi lengkung. Oleh karenanya, media SGF yang telah dikembangkan dapat dimanfaatkan guru SMP untuk meningkatkan hasil belajar siswa kemudian siswa juga dapat 
belajar mandiri di rumah. Media ini masih terbatas dalam penggunaannya, oleh karena itu diharapkan penelitian selanjutnya dapat mengembangkan media SGF lebih baik dan membuat inovasi-inovasi baru lagi.

\section{DAFTAR PUSTAKA}

Aditya, P. T. (2018). Pengembangan Media Pembelajaran Matematika Berbasis Web Pada Materi Lingkaran Bagi Siswa Kelas Viii. Jurnal Matematika Statistika Dan Komputasi, $\quad$ 15(1), 64. https://doi.org/10.20956/jmsk.v15i 1.4425

Ainiyah, L. A., \& Sugiyono. (2016). Identifikasi Miskonsepsi Siswa Dalam Materi Geometri Pada Pembelajaran Matematika Siswa Kelas Viii Smp Negeri 1 Punggelan. Jurnal Pendidikan Matematika-S1, 5(1), 10.

Andini, S., Fitriana, L., \& Budiyono, B. (2018). Geometry in flipbook multimedia, a role of technology to improve mathematics learning quality: The case in madiun, east Java. Journal of Physics: Conference Series. https://doi.org/10.1088/17426596/1008/1/012077

Assar, S. (2015). Information and Communications Technology in Education. In International Encyclopedia of the Social \& Behavioral Sciences: Second Edition.

https://doi.org/10.1016/B978-0-08097086-8.92104-4

Astuti, I. P. (2019). Ruang Sisi Lengkung Dengan Model Discovery Learning Terbimbing Berbantuan Media Serbaneka. JANACITTA : Journal of Primary and Children's Education, 2(September). Retrieved from http://jurnal.unw.ac.id/index.php/ja nacitta

Chaidar, H. (2014). Pemanfaatan Teknologi Informasi dan Komunikasi dalam Pembelajaran di SMA Muhammadiyah Tarakan. Jurnal Kebijakan Dan Pengembangan Pendidikan, 2(2), 184-192.

Fitria, A. D., Mustami, M. K., \& Taufiq, A. U. (2017). Pengembangan Media Gambar Berbasis Potensi Lokal Pada Pembelajaran Materi Keanekaragaman Development of Picture Media Based on Local Potency for Learning Materials Biodiversity in. AULADUNA: Jurnal Pendidikan Dasar Islam, 4(2), 14-28. Retrieved from http://journal.uin-

alauddin.ac.id/index.php/auladuna/ article/view/5176

Haryanti, F., \& Saputro, B. A. (2016). Pengembangan Modul Matematika Berbasis Dicovery Learning Berbantuan Fipbook Maker Uuntuk Meningkatkan Kemampuan Pemahaman Konsep Siswa Pada Materi Segitiga. KALAMATIKA Jurnal Pendidikan Matematika.

https://doi.org/10.22236/kalamatik a.vol1no2.2016pp147-161

Hayati, N., Ahmad, M. Y., \& Harianto, F. (2017). Hubungan Penggunaan Media Pembelajaran Audio Visual dengan Minat Peserta Didik pada Pembelajaran Pendidikan Agama Islam di SMAN 1 Bangkinang Kota. Jurnal Al-Hikmah, 14(2), 160-180. 
Hayati, S., Budi, A. S., \& Handoko, E. (2015). Pengembangan Media Pembelajaran Flipbook Fisika untuk Meningkatkan Hasil Belajar Peserta Didik. Prosiding Seminar Nasional Fisika (e-Jurnal) SNF2015, IV, 49-54.

Iswara, N., Ariyanto, \& Sutarni, S. (2012). Penerapan Metode Pembelajaran Scaffolding Dalam Pembelajaran Matematika Sebagai Upaya Peningkatan Hasil Belajar Matematika Siswa Kelas VII SMP Negeri 1 Polokarto Tahun Ajaran 2011/2012. Fkip Ums, 1-17. Retrieved from http://eprints.ums.ac.id/21128/17/ Naskah_Publikasi.pdf

Kurniawati, J., \& Baroroh, S. (2016). Literasi media digital mahasiswa Universitas Muhammadiyah Bengkulu. Jurnal Komunikator, 8(2), 51-66. Retrieved from http://journal.umy.ac.id/index.php/j $\mathrm{km} /$ article/view/2069

Lestari, E., Sunardi, \& Suryani, N. (2017). Jurnal Penelitian Teknologi Pendidikan

http://jurnal.fkip.uns.ac.id/teknodik a. Teknodika, Jurnal Penelitian Teknologi Pendidikan, 15(01), 1625.

Nurseto, T. (2012). Membuat Media Pembelajaran yang Menarik. Jurnal Ekonomi Dan Pendidikan. https://doi.org/10.21831/jep.v8i1.7 06

Puspa Putri, D. A. (2019). Rancang Bangun Media Pembelajaran Bahasa Arab Untuk Anak Usia Dini Berbasis Android. Technologia: Jurnal Ilmiah, 10(3),
156.

https://doi.org/10.31602/tji.v10i3.2 230

Putri, O. R. U., \& Zukhrufurrohmah, Z. (2019). PENGEMBANGAN LEMBAR KEGIATAN KALKULUS BERCIRIKAN REPRESENTASI MATEMATIS. AKSIOMA: Jurnal Program Studi Pendidikan Matematika. https://doi.org/10.24127/ajpm.v8i3. 2259

Rahayu, T., \& Mayasari, T. (2018). Profil kemampuan awal literasi digital dalam pembelajaran fisika siswa SMK Kota Madiun. Seminar Nasional Quantum, 25, 431-437. Retrieved from http://seminar.uad.ac.id/index.php/ quantum/article/download/294/244

Setyono, T., Eka, L., Deswita, H., \& Belakang, A. L. (2017). Pengembangan Media Pembelajaran Matematika Dengan Menggunakan Macromedia Flash Pada Materi Bangun Ruang Kelas VIII Sekolah Menengah Pertama. Jurnal Fakultas Keguruan Dan Ilmu Pendidikan Universitas Pasir Pengaraian, 2(1), 1-10.

Suryani, N. (2016). Pengembangan Media Pembelajaran Sejarah Berbasis It. Sejarah Dan Budaya: Jurnal Sejarah, Budaya, Dan Pengajarannya, 10(2), 186-196. https://doi.org/10.17977/um020v10 i22016p186

Syarifuddin, \& Muadip. (2016). Pengaruh Penggunaan Media Audio Visual Terhadap Hasil Belajar Siswa Kelas $\mathrm{X}$ Bahasa SMA Al-Ashriyyah Nurul Iman 
DOI: https://doi.org/10.24127/ajpm.v9i3.2951

Parung-Bogor. Jurnal Educate, 1(1), 77-102.

Tim GLN Kemendikbud. (2017). Materi Pendukung Literasi Digital. Kementerian Pendidikan Dan Kebudayaan, 43. Retrieved from http://gln.kemdikbud.go.id/glnsite/ wpcontent/uploads/2017/10/literasiDigital.pdf

Triastuti, D., Irawan, edi bambang, \& Akbar, S. (2017). Penggunaan Media Papan Permainan Untuk Meningkatkan Motivasi Belajar Siswa Di Sekolah Dasar. Penggunaan Media Papan Permainan Untuk Meningkatkan Motivasi Belajar Siswa Di Sekolah Dasar, 1-7.

Willy Arif Indhaka, Eko Supraptono, N. S. (2016). Penerapan Buku Sekolah Elektronik Berbasis Android Dalam Materi Ajar Besaran Dan Satuan. Didaktikum: Jurnal Penelitian Tindakan Kelas, 17(2), 1-8. 